\section{Oxygen tension-independent protection against hypoxic cell killing in rat liver by low sodium}

\author{
Andrea Ferrigno, Laura G. Di Pasqua, \\ Clarissa Berardo, Veronica Siciliano, \\ Plinio Richelmi, Mariapia Vairetti
}

Department of Internal Medicine and Therapeutics, University of Pavia, Italy

\begin{abstract}
The role of $\mathrm{Na}^{+}$in hypoxic injury was evaluated by a time-course analysis of damage in isolated livers perfused with $\mathrm{N}_{2}$-saturated buffer containing standard (143 mM) or low $(25 \mathrm{mM}) \mathrm{Na}^{+}$levels. Trypan blue uptake was used to detect non-viable cells. Under hypoxia with standard- $\mathrm{Na}^{+}$, trypan blue uptake began at the border between pericentral areas and periportal regions and increased in the latter zone; using a low- $\mathrm{Na}^{+}$ buffer, no trypan blue zonation occurred but a homogenous distribution of dye was found associated with sinusoidal endothelial cell (SEC) staining. A decrease in hyaluronic acid (HA) uptake, index of SEC damage, was observed using a low- $\mathrm{Na}^{+}$buffer. A time dependent injury was confirmed by an increase in LDH and TBARS levels with standard- $\mathrm{Na}^{+}$buffer. Using low- $\mathrm{Na}^{+}$buffer, SEC susceptibility appears elevated under hypoxia and hepatocytes was protected, in an oxygen independent manner.
\end{abstract}

\section{Introduction}

The liver is characterized by a unique vascularization in which afferent blood flow derives from both hepatic artery (oxygenated blood) and portal vein (deoxygenated blood). The directional flow of mixed oxygenated and deoxygenated blood toward the central vein of the hepatic lobule is responsible of the physiological oxygen gradient formation. The oxygen gradient ranges from about $60-65 \mathrm{mmHg}$ in the periportal blood to about $30-35 \mathrm{mmHg}$ in periportal zone. ${ }^{1}$ In response to changes in the oxygen availability, hypoxic inducible factors (HIFs) are involved in the regulation of gene expression: HIF-1alpha is responsible to an acute response to low $\mathrm{O}_{2}$ concentration, whereas HIF-2alpha responds to pathological situation in which a chronic hypoxia occurs. Interruption of blood flow followed by reperfusion of the organ leads to significant cellular damage; this event occurs during hepatic surgery such as liver transplantation and major resection. During conventional organ transplantation, after cold storage (CS) preservation, the liver is subjected to hypoxic injury, detrimental for organ function and long-term graft survival. ${ }^{2,3}$

In the attempt to avoid hypoxia, new organ preservation techniques were evaluated such as the use of machine perfusion (MP). MP is a dynamic preservation technique in which a continuous circulation of filtered preservation solution maintains and delivers metabolic substrates to the entire vasculature of the donor liver. In the first clinical trials, HIF-1-alpha was significantly upregulated in the CS but not in hypothermic MP. ${ }^{4}$ Low HIF-1alpha levels were also expressed during liver preservation by MP performed at $20^{\circ} \mathrm{C} ; ;^{5}$ marginal organs such as fatty livers are better preserved by $\mathrm{MP}$ at $20^{\circ} \mathrm{C}$ when compared with conventional CS..$^{6,7}$

Previous studies showed that alterations in $\mathrm{Na}^{+}$homeostasis represent a critical step in the development of hepatocyte damage during hypoxia. ${ }^{8}$ Based on the above observation, the aim of this work is to evaluate the time-course effects of hypoxia in isolated perfused liver using two different $\mathrm{Na}^{+}$ concentration medium (standard and low$\mathrm{Na}^{+}$concentrations) and correlate the changes with the hepatic oxygen gradient.

\section{Materials and Methods}

\section{Materials}

All reagents were of the highest grade of purity available and were obtained from local suppliers.

\section{Animals}

The use of animals in this experimental study was approved by the National Institute for Research, and the animals were cared for according to its guidelines (Approval number: 2/2012). Male Wistar rats (200-250 g) were given standard chow and water ad libitum and then fasted 24 hours before the beginning of the perfusion experiments. Twenty-four rats were anaesthetized with sodium pentobarbital (40 $\mathrm{mg} / \mathrm{kg}$ i.p.) and received 250 units of heparin via inferior vena cava prior to liver isolation. Livers were washed out with standard Krebs-Henseleit (KH) medium containing $118 \mathrm{mM} \mathrm{NaCl}, 4.7 \mathrm{mM} \mathrm{KCl}, 1.2$ $\mathrm{mM} \mathrm{MgSO} 4,1.2 \mathrm{mM} \mathrm{KH} \mathrm{PO}_{4}, 2.5 \mathrm{mM}$ $\mathrm{CaCl} 2,25 \mathrm{mM} \mathrm{NaHCO}{ }_{3}$ and $20 \mathrm{mM}$ HEPES (pH 7.4) at a rate of $3 \mathrm{ml} / \mathrm{min} / \mathrm{g}$ of
Correspondence: Mariapia Vairetti, Department of Internal Medicine and Therapeutics, University of Pavia, Via A. Ferrata 9/A, 27100 Pavia, Italy.

Tel. +39.0382.986398; Fax: +39.0382.986347.

E-mail: mariapia.vairetti@unipv.it

Key words: Liver; hypoxia; $\mathrm{Na}^{+}$; hepatocytes; sinusoidal endothelial cells.

Contributions: MV, AF, designed experiments, analysed data, wrote the draft and approved the final version; LGDPD, CB, VS, performed experiments and analysed data; PR, revised the draft and approved of the final version.

Conflict of interest: all authors declare no conflict of interest related to this publication.

Acknowledgments: we thank Dr. Roberto Imberti for the discussion of the results. We thank Mr. Massimo Costa for the skillful technical assistance and Mrs. Nicoletta Breda for the editing assistance.

Received for publication: 11 April 2017. Accepted for publication: 13 May 2017.

This work is licensed under a Creative Commons Attribution-NonCommercial 4.0 International License (CC BY-NC 4.0).

(C) Copyright A. Ferrigno et al., 2017

Licensee PAGEPress, Italy

European Journal of Histochemistry 2017; 61:2798 doi:10.4081/ejh.2017.2798

liver and maintained at $37^{\circ} \mathrm{C}$ under a continuous flow of $95 \% \mathrm{O}_{2}$ and $5 \% \mathrm{CO}_{2}$ mixture. In low-Na ${ }^{+} \mathrm{KH}, 118 \mathrm{mM}$ choline chloride was used in substitution of $\mathrm{NaCl}(25$ $\mathrm{mM}$ final concentration). The liver was placed in an organ chamber and connected to circulating standard perfusion equipment. The KH solution was circulated by the roller pump (Gilson Miniplus-3), oxygenated and maintained at $37^{\circ} \mathrm{C}$ by a heat exchanger (Julabo-F12). Air emboli were removed from the system by a bubble trap. During liver perfusion, the amount of oxygen dissolved in the influent-perfusate was measured using a Clark-type oxygen electrode: hypoxia was induced using $\mathrm{KH}$ medium equilibrated with $95 \% \mathrm{~N}_{2}$ and $5 \% \mathrm{CO}_{2}$ and it was obtained when the oxygen amount was about $6 \pm 1 \mu \mathrm{mol} / \mathrm{L}{ }^{9}$

\section{Trypan blue uptake}

At the end of each experiment, samples were prepared for histology by a 7-min perfusion with $\mathrm{KH}$ containing $200 \mu \mathrm{mol} / \mathrm{L}$ trypan blue immediately followed by fixation with Bouin's solution for $2 \mathrm{~min}$. The fixed tissue was embedded in paraplast and pro- 
cessed for light microscopy. ${ }^{10}$ Non-viable cells were identified by trypan blue nuclear staining, in tissue sections stained with eosin or hematoxylin/eosin (E/E).

\section{Biochemical assays}

Liver viability was evaluated at $10 \mathrm{~min}$ intervals by measuring release of lactate dehydrogenase (LDH) into the effluent-perfusate buffer, expressed in $\mathrm{mU} / \mathrm{min} / \mathrm{g}$ liver weight. ${ }^{11}$ Lipid peroxidation was monitored in the perfusate by measuring the formation of thiobarbituric acid-reactive substances (TBARS). ${ }^{12}$ In order to evaluate the endothelial cell function, the hyaluronic acid (HA) test was used, since sinusoidal endothelial cells (SECs) take up and metabolize more than $90 \%$ of circulating HA. ${ }^{7}$ HA $(150 \mu \mathrm{g} / \mathrm{L})$ was infused in the reservoir to achieve a steady state level. The percentage of HA taken up by SECs during hypoxia was used as a parameter for SEC function. HA uptake was evaluated by a sandwichbinding enzyme assay (Chugai Corp., Tokyo, Japan).

\section{Statistical analysis}

Results are expressed as mean \pm standard error (SE). Comparisons between groups were performed by unpaired $t$-test. When data distribution was not normal according to the Kolmogorov-Smirnov test, the Mann-Whitney test was used. Biochemical parameters were also analyzed by one-way ANOVA and where necessary by Kruskall-Wallis Test.

\section{Results}

In this study, hepatic damage was assessed in hypoxic perfusion, using $\mathrm{N}_{2}$-saturated $\mathrm{KH}$ with both standard or low- $\mathrm{Na}^{+}$ concentrations, at 10, 40 and 70 min intervals by trypan blue in situ evaluation of necrosis. Under hypoxia in presence of standard- $\mathrm{Na}^{+}$concentration, liver section stained with eosin showed a time-dependent increase of zone-specific necrosis as demonstrated by trypan blue uptake (Figure 1). At 40 min necrotic, both parenchymal and non-parenchymal cells, were located at the border between pericentral areas and periportal regions, and increased in this last zone after $70 \mathrm{~min}$ (Figure $1 \mathrm{C}, \mathrm{E}$ ). On the contrary, under hypoxia in low- $\mathrm{Na}^{+}$buffer, no trypan blue zonation occurred but a homogenous distribution of dye was found in endothelial cells after $40 \mathrm{~min}$ (Figure 1D). A low hepatocyte damage was found at 70 min using low- $\mathrm{Na}^{+}$medium (Figure 1F). Tissue sections obtained after hypoxia and stained with E/E showed that the morpho- logical identification of necrotic cells stained by trypan blue was possible also when hematoxylin was used (Figure 2). Actually, in the E/E stained sections the identification of trypan-blue-positive (necrotic) hepatocytes is still possible due to their large cytoplasm, but this is not the case for sinusoidal endothelial cells. No trypan blue staining was observed in normoxic perfusion with standard or low-Na+ $\mathrm{KH}$ (data not shown).

When evaluating the SEC damage, the HA uptake test was performed: a significant decrease in HA uptake was observed in the livers submitted to hypoxia in a low- $\mathrm{Na}^{+}$ medium when compared with standard- $\mathrm{Na}^{+}$ $\mathrm{KH}(\mu \mathrm{g} / \mathrm{g} / \mathrm{h}: 6 \pm 0.4$ versus $12 \pm 0.9$ respectively, $\mathrm{P} \leq 0.05$, at $40 \mathrm{~min}$ ).

Using a standard- $\mathrm{Na}^{+}$concentration, the time dependent injury that occurs under hypoxia was confirmed using perfusate samples: hepatic LDH release and TBARS levels, indexes of necrosis and oxidative stress, respectively, started at $30 \mathrm{~min}$ and increase up to the end of experiments ( 70 min) (Figure 3). A restricted level in LDH
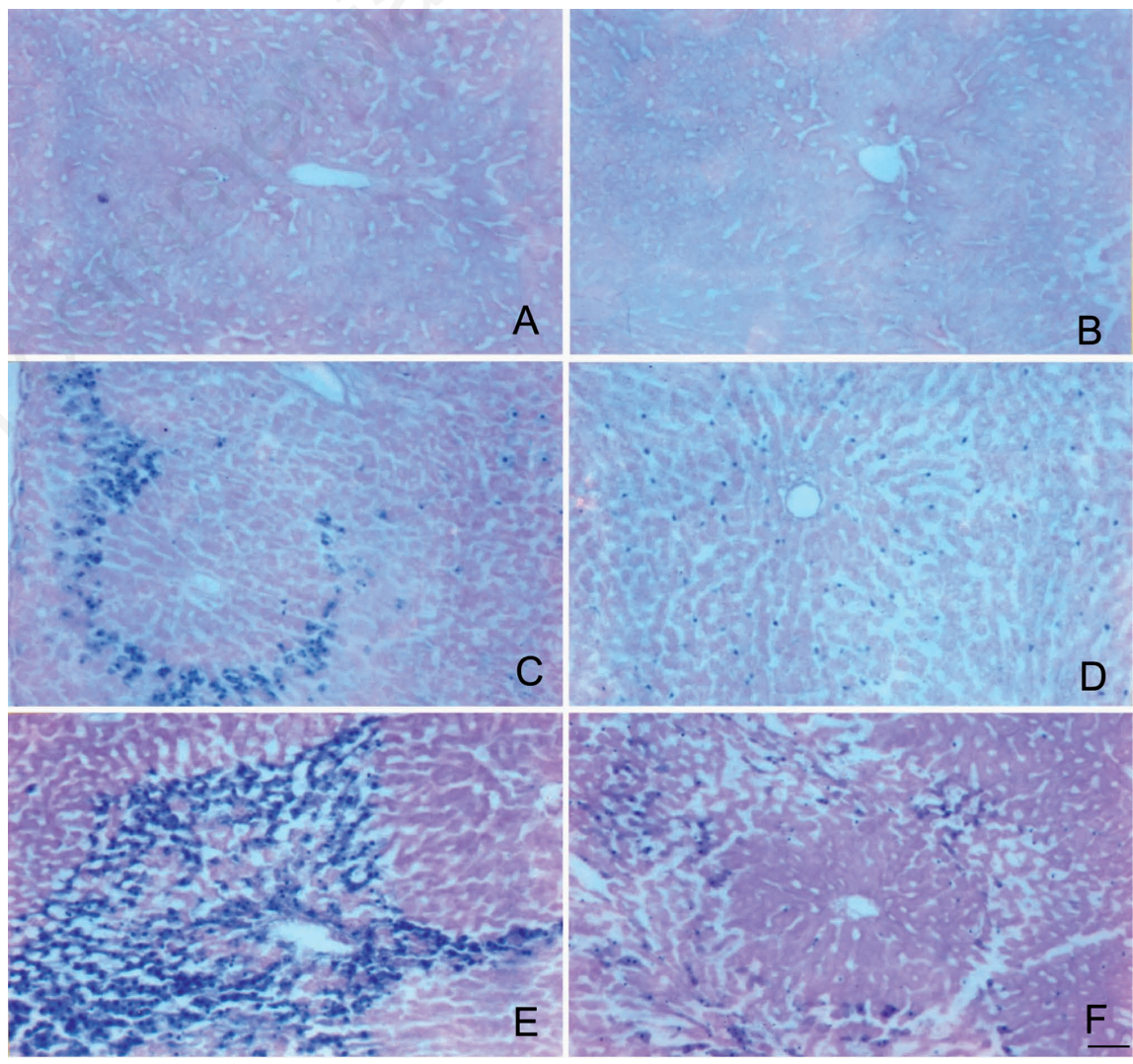

Figure 1. Eosin staining and trypan blue uptake in hypoxic livers after perfusion with standard or low- $\mathrm{Na}^{+}$Krebs Henseleit $(\mathrm{KH})$ buffers. Hypoxic perfusion with standard-Na+ concentration at $10 \mathrm{~min}(\mathrm{~A}), \mathbf{4 0} \mathrm{min}(\mathrm{C})$ and $70 \mathrm{~min}(\mathrm{E})$. Hypoxic perfusion with low$\mathrm{Na}^{+}$concentration at $10 \mathrm{~min}(\mathrm{~B}), 40 \mathrm{~min}(\mathrm{D})$ and $70 \mathrm{~min}(\mathrm{~F})$. Scale bars: $100 \mu \mathrm{m}$. 
gradient across the liver lobule, with lower oxygen tension in the perivenous regions. In the isolated perfused rat liver, early trypan blue staining occurred in the zone between pericentral areas and periportal regions using an $\mathrm{N}_{2}$ saturated $\mathrm{KH}$, in agreement with previous results obtained during low-flow hypoxia. ${ }^{14}$ In our model, in which a $\mathrm{N}_{2}$-saturated $\mathrm{KH}$ was used, the hepatocyte damage started at 40 min using standard$\mathrm{Na}^{+} \mathrm{KH}$ affecting the periportal region where an increased necrosis was detected at
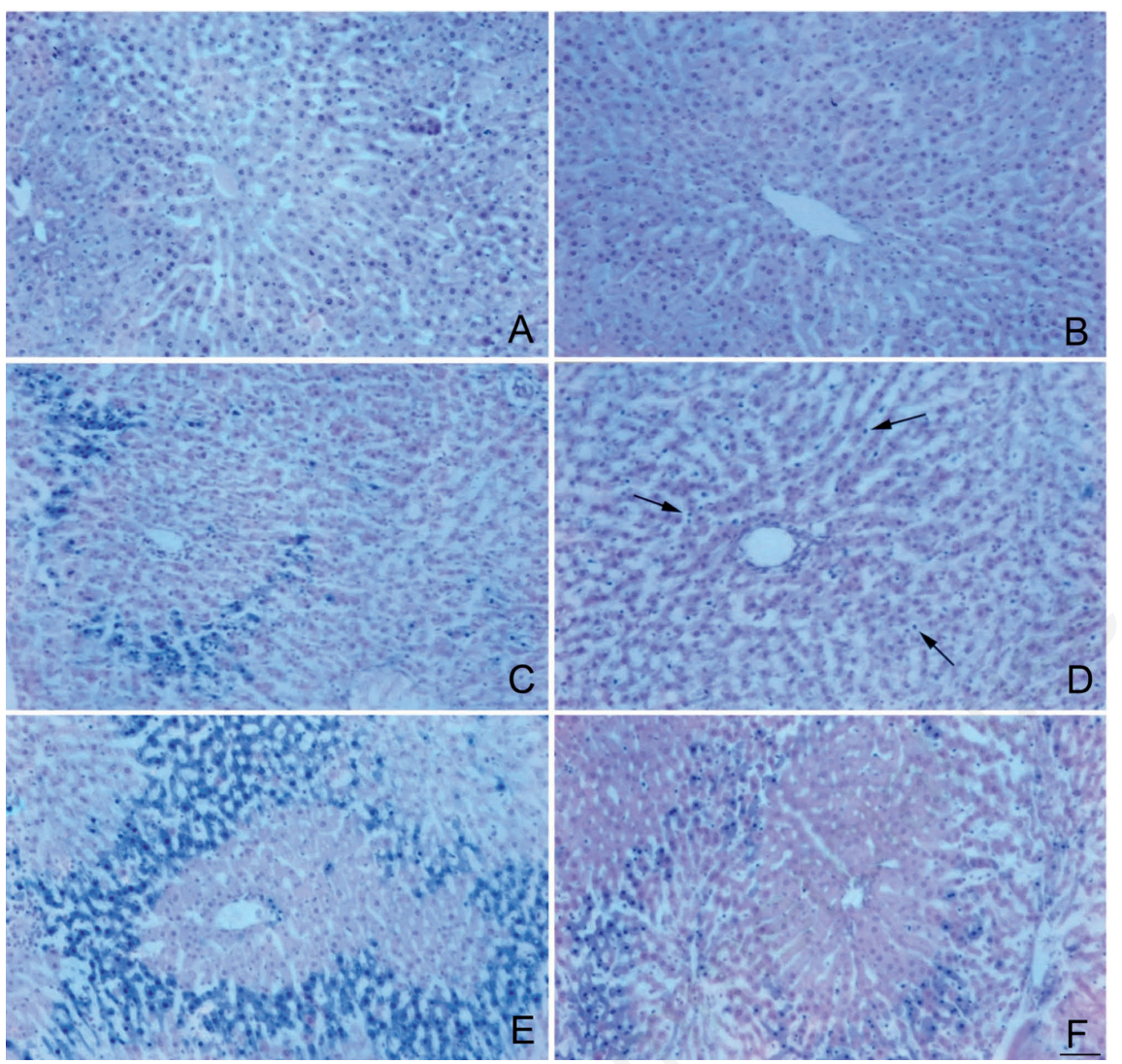

Figure 2. Hematoxylin/eosin (E/E) staining and trypan blue uptake in hypoxic livers after perfusion with standard or low- $\mathrm{Na}^{+} \mathrm{Krebs}$ Henseleit $(\mathrm{KH})$ buffers. Hypoxic perfusion with standard- $\mathrm{Na}^{+}$concentration at $10 \mathrm{~min}(\mathrm{~A}), 40 \mathrm{~min}(\mathrm{C})$ and $70 \mathrm{~min}(\mathrm{E})$. Hypoxic perfusion with low- $\mathrm{Na}^{+}$concentration at $10 \mathrm{~min}(\mathrm{~B}), 40 \mathrm{~min}(\mathrm{D})$ and $\left.70 \mathrm{~min}(\mathrm{~F}) . \mathrm{D}\right)$ arrows denote sinusoidal endothelial cells (SECs). Scale bars: $100 \mu \mathrm{m}$.
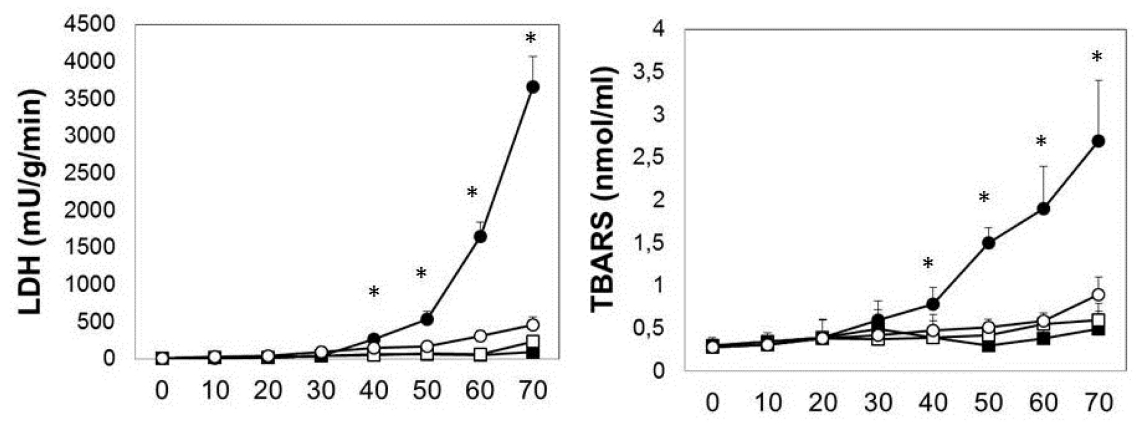

-Standard-Na+ Normoxia $\rightarrow-$ Low-Na+ Normoxia

Standard-Na+ Hypoxia $\quad-$-Low-Na+ Hypoxia

Figure 3. LDH release (Panel A) and TBARS formation (Panel B) in livers under normoxic and hypoxic perfusion. Krebs Henseleit $(\mathrm{KH})$ buffer with standard or low- $\mathrm{Na}^{+}$concentration was used. The results are reported as the mean $\pm S E$ of 6 different experiments. ${ }^{*} \mathrm{P} \leq \mathbf{0 . 0 5}$ vs low- $\mathrm{Na}^{+}$hypoxia.

$70 \mathrm{~min}$. These events were associated with a concomitant time-dependent increase in lipid peroxidation, thus confirming the crucial role of reactive oxygen species (ROS) during hypoxia. On the contrary, using a low- $\mathrm{Na}^{+} \mathrm{KH}$, the hepatocytes were markedly protected, whereas SECs were homogenously stained with trypan blue. The use of a low- $\mathrm{Na}^{+} \mathrm{KH}$ markedly protected hepatocytes but not SECs: the reduced HA uptake reflects an impaired SEC function caused by low- $\mathrm{Na}^{+}$hypoxia. SECs constitute the sinusoidal wall that differs from that of other capillaries in the body because of the presence of open pores and the lack of an organized basement membrane that optimize the oxygen deliver. ${ }^{15}$ During organ transplantation, prolonged cold ischemia time during graft preservation and warm hypoxia $\left(37^{\circ} \mathrm{C}\right)$, occurring during the rewarming time, have been reported to cause postoperative graft dysfunction. The vulnerability of SECs appears in cold ischemia/reperfusion injury: SECs are believed to be the primary target cells of this kind of injury. ${ }^{16}$ Here we demonstrated that the use of a low $\mathrm{Na}^{+}$concentration medium changes the SEC susceptibility during hypoxia performed at $37^{\circ} \mathrm{C}$.

In conclusion, using a standard- $\mathrm{Na}^{+}$ $\mathrm{KH}$, hepatocyte injury, confirmed by LDH and TBARS levels, was the prominent feature in hypoxic livers at $37^{\circ} \mathrm{C}$ versus SEC vulnerability that was predominant in cold hypoxic organs. ${ }^{17}$ On the contrary, using low- $\mathrm{Na}^{+} \mathrm{KH}$, SEC susceptibility appears particularly elevated under hypoxia at $37^{\circ} \mathrm{C}$ and hepatocytes were efficiently protected, in an oxygen independent manner. The complex interplay between oxygen gradient and different cell type response should be further elucidated.

\section{References}

1. Kietzmann T, Dimova EY, Flügel D, Scharf J-G. Oxygen: modulator of physiological and pathophysiological processes in the liver. Z Gastroenterol 2006;44:67-76.

2. Ferrigno A, Carlucci F, Tabucchi A, Tommassini V, Rizzo V, Richelmi P, et al. Different susceptibility of liver grafts from lean and obese Zucker rats to preservation injury. Cryobiology 2009;59:327-34.

3. Akhtar MZ, Sutherland AI, Huang H, Ploeg RJ, Pugh CW. The role of hypoxia-inducible factors in organ donation and transplantation: the current perspec- 
tive and future opportunities. Am J Transplant 2014;14:1481-7.

4. Henry SD, Nachber E, Tulipan J, Stone J, Bae C, Reznik L, et al. Hypothermic Machine Preservation Reduces Molecular markers of ischemia/reperfusion injury in human liver transplantation. Am J Transplant 2012;12:2477-86.

5. Ferrigno A, Di Pasqua LG, Bianchi A, Richelmi P, Vairetti M. Metabolic shift in liver: Correlation between perfusion temperature and hypoxia inducible factor-1? World J Gastroenterol 2015;21: 1108-16.

6. Boncompagni E, Gini E, Ferrigno A, Milanesi G, Gringeri E, Barni S, et al. Decreased apoptosis in fatty livers submitted to subnormothermic machineperfusion respect to cold storage. Eur J Histochem 2011;55:e40.

7. Vairetti M, Ferrigno A, Carlucci F, Tabucchi A, Rizzo V, Boncompagni, E et al. Subnormothermic machine perfusion protects steatotic livers against preservation injury: a potential for donor pool increase? Liver Transpl 2009;15:20-9.

8. Carini R, De Cesaris MG, Bellomo G,
Albano E. Intracellular $\mathrm{Na}+$ accumulation and hepatocyte injury during cold storage. Transplantation 1999;68:294-7.

9. Vairetti M, Carini R, De Cesaris MG, Splendore R, Richelmi P, Bertè F, et al. Beta-alanine protection against hypoxic liver injury in the rat. Biochim Biophys Acta - Mol Basis Dis 2002;1587:83-91.

10. Croce AC, De Simone U, Vairetti M, Ferrigno A, Boncompagni E, Freitas I, et al. Liver autofluorescence properties in animal model under altered nutritional conditions. Photochem Photobiol Sci 2008;7:1046-53.

11. Vairetti M, Ferrigno A, Rizzo V, Richelmi P, Boncompagni E, Neri D, et al. Subnormothermic machine perfusion protects against rat liver preservation injury: A Comparative evaluation with conventional cold storage. Transplant Proc 2007;39:1765-7.

12. Palladini G, Ferrigno A, Rizzo V, Boncompagni E, Richelmi P, Freitas. I et al. Lobe-specific heterogeneity and matrix metalloproteinase activation after ischemia/reperfusion injury in rat livers. Toxicol Pathol 2012;40:722-30. 13. Vairetti M, Richelmi P, Bertè F, Currin
RT, Lemasters JJ, Imberti R. Role of $\mathrm{pH}$ in protection by low sodium against hypoxic injury in isolated perfused rat livers. J Hepatol 2006;44:894-901.

14. Marotto ME, Thurman RG, Lemasters JJ. Early midzonal cell death during low-flow hypoxia in the isolated, perfused rat liver: protection by allopurinol. Hepatology 8:585-90.

15. Lasnier E, Blanc MC, Housset C, Rey C, Roch-Arveiller M, Vaubourdolle M. Cytotoxic response of sinusoidal endothelial cells to polymorphonuclear leukocytes and its potential implication in hypoxia-reoxygenation injury. Liver 2002;22:495-500.

16. Ferrigno A, Tartaglia A, Di Nucci A, Bertone V, Richelmi P, Neri D, et al. Further studies on long-term preservation of rat liver: Celsior versus UW solution. In Vivo (Brooklyn) 2008;22: 681-6.

17. Samarasinghe DA, Farrell GC. The central role of sinusoidal endothelial cells in hepatic hypoxia-reoxygenation injury in the rat. Hepatology 1996;24: 1230-7. 